\title{
Dynamic voltage restorer using sliding mode controller: Experimental studies
}

\author{
Toumi Toufik ${ }^{1}$, Benabedellah Abdelkader ${ }^{2}$, Abdelkhalek Othmane $^{3}$, Allali Ahmed ${ }^{4}$, Benhamou Aissa ${ }^{5}$, \\ Hafsi Oussama ${ }^{6}$ \\ ${ }^{1,2,3,5,6}$ Faculty of Technology, University of Tahri Mohammed Bechar, Smart Grids \& Renewable Energies Laboratory, \\ Bechar, Algeria \\ ${ }^{4}$ Faculty of Electrical Engineering, University of Sciences and Technology of Oran. LDDEE, Sustainable Development \\ of Electrical Energy, Bechar, Algeria
}

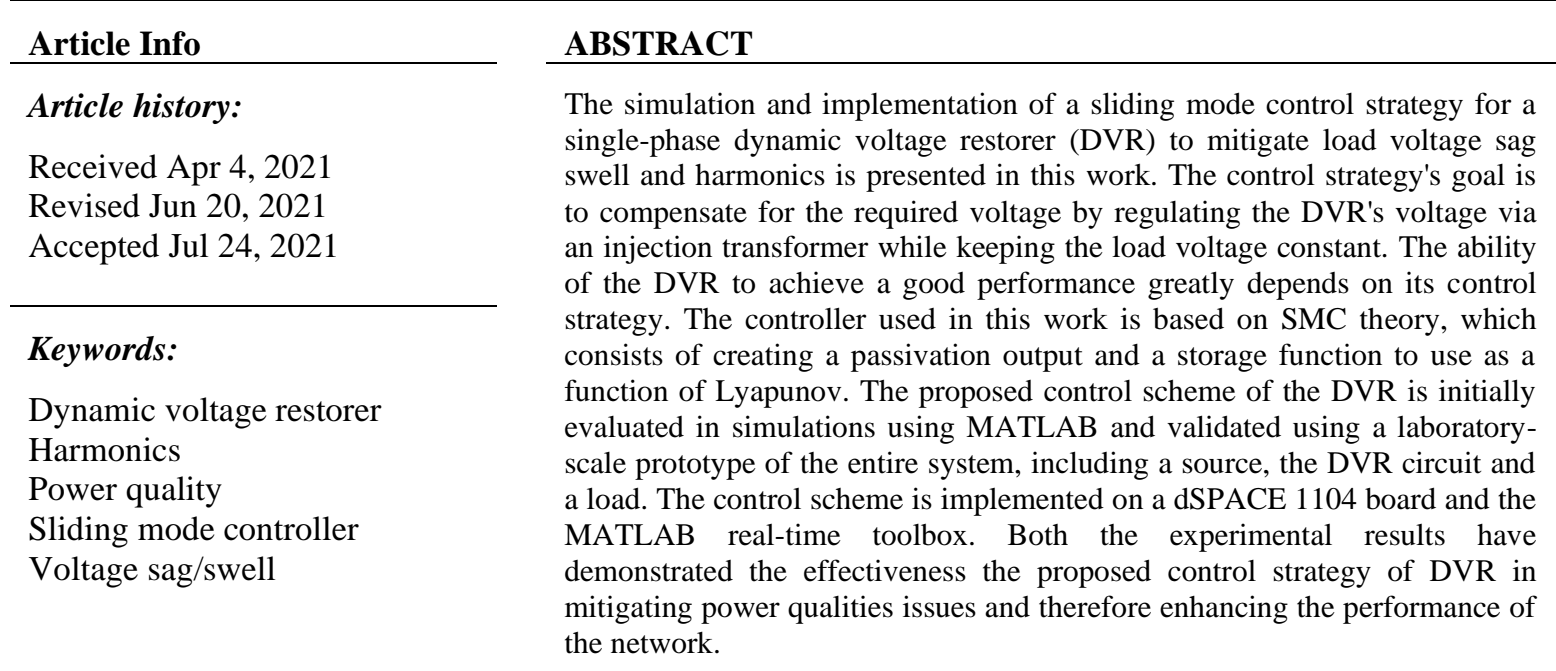

This is an open access article under the $\underline{C C B Y-S A}$ license.

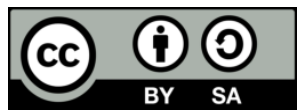

\section{Corresponding Author:}

Toumi Toufik

Department of Electrical of Engineering

Tahri Mohammed Bechar University

BP 417 Route de Kenadsa, 08000 Bechar, Alegria

Email: toufiktoumi@yahoo.fr

\section{INTRODUCTION}

Grid failures caused by the power quality disturbances such as voltage sags and swells can severely affect the sensitive loads of the electrical power systems [1], and causes about $90 \%$ of average customer outages [2]. The dynamic voltage restorer (DVR) is an economical and technically effective solution for protecting sensitive loads from power quality disturbances such as voltage dips, according to research in the field of power quality improvement [3].

During a voltage disturbance, such as a voltage sag/swell, the connection node receives the necessary compensating voltage with the needed amplitude and frequency to restore the load voltage to its normal value. The DVR trades active and reactive power with the load during this operation. In the event of voltage sag, various energy storage devices such as batteries, capacitors, and flywheels are employed in conjunction with the DVR to provide the required active power. 
DVRs have been proposed with a variety of topologies and control systems. There are two types of topologies that can be classified. AC/DC/AC conversion is used by the first category. A mains transformer (source side or load side) provides the appropriate DC voltage via a rectifier in this scenario. The energy required for voltage adjustment is given via an inverter from a DC capacitor or another energy storage device such as a double-layer capacitor, a super conducting magnetic energy storage device, or a lead-acid battery via an inverter [4], [5].

The proportional-integral (PI) controller and other classical linear controllers have been widely utilized in power quality to perform online adjustment of voltage or current fluctuations to protect sensitive equipment. Generally, the sinusoidal pulse width modulation (SPWM) is used as a switching method for the DVR circuits. Recently, a new switching approach for DVR using one cycle control method has been proposed [6]. This method can remove several types of voltage disturbances with a higher performance than the classical PWM for DVRs applications.

Recently, a method named single-phase SRFT (Single phase SRF d-q theory) which generates a reference for the injected voltage has been proposed and applied to the design of the DVR controller. This controller has proved its effectiveness in mitigating the voltage sags of a distorted voltage based on the moving average filter [7]. Different single-phase DVR topologies have been studied and compared with the conventional schemes [8]-[10]. In [11], the authors discussed single-phase DVR design and control. The DVR can provide bidirectional energy flow with the proposed mix of series and shunt converters. To compensate for sag and swell, DVRs based on H-bridge converters connected in back-to-back arrangement with a common dc-link capacitor.

The reliability of the DVR can be enhanced by the proper selection of the control method. Several control schemes have been proposed which can basically be classified into two types: linear and nonlinear control. Linear controls techniques such as direct control, feedback control and composite control do not usually lead to good performance due to inherent nonlinear characteristics of the inverter switching devices [12], [13].

In this paper, the design of single-phase DVR based on H-bridge converters is presented. The aim is to maintain the load voltage amplitude at the desired level for all operating conditions. A sliding mode controller is proposed in this work. SM has long been known for its ability to deal with non linearities and uncertainties in the system model and has been successful in many real-world applications. The rest of the paper is organized as follows: The DVR's operating principle is described in Section 2, its configuration, and its different operating modes Section 3 presents the model of the system and the proposed control scheme of the DVR. Some simulation results for a linear load are also included in Section 2. Section 4 describes the experimental set-up of the low-voltage DVR prototype and presents some results of the validation of the proposed control scheme. Conclusions are summarized in Section 5 of the paper.

\section{PRINCIPLE OF OPERATION OF THE DVR}

\subsection{System configuration}

A typical single-line arrangement of the DVR attached to the distribution system is shown in Figure 1. A booster transformer is connected in series with a voltage source inverter (VSI), an energy storage system, and a capacitor in DC link to make up the circuit. Instead of the VSI, other topologies employ an AC-AC converter, which eliminates the DC link from the circuit [14], [15].

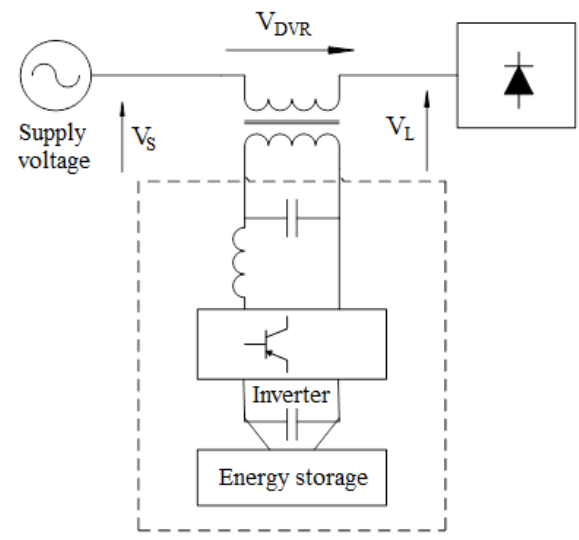

Figure 1. Typical DVR structure 


\subsection{Equivalent circuit}

Figure 2 shows the single-line equivalent circuit of a single-phase system of a distribution feeder with a DVR. In this simplified equivalent circuit, it is assumed that the supply voltage, the DVR injection voltage and the load voltage are in series. The purpose is to maintain the amplitude of the load voltage at a fixed level and prevent phase jumps. In Figure 2, $V_{g}(t), V_{D V R}$ and $V_{L}(t)$ denote the grid voltage, the DVR output voltage (injected to the grid), and the load voltage respectively. The grid Thevenin voltage and impedance of the DVR are denoted by $V_{s}(t)$ and $Z_{g}$, respectively. $V_{c}(t)$ represented the fundamental component of the converter output voltage.

Through a coupling transformer, the DVR injects a regulated voltage in series with the bus voltage. The injected phase voltages' amplitudes are adjusted to prevent the load voltage from being harmed by a bus fault. The load bus failure level determines the system impedance $Z_{t h}$. The DVR injects a series voltage $\mathrm{V}$ DVR to maintain the required load voltage magnitude $V_{L}$. when the system voltage $V_{t h}$ decreases. The DVR's series injected voltage can be written as (1) and (2).

$$
\begin{aligned}
& V_{D V R}=V_{L}+Z_{t h} * I_{L}-V_{t h} \\
& I_{L}=\frac{P_{L}+j Q_{L}}{V_{L}}
\end{aligned}
$$

Where, the voltage, current and impedance of the load are denoted by $V_{L}, I_{L}$ and $Z_{t h}$, respectively

\subsection{DVR operating modes}

The DVR has three modes of operation: standby, injection, and protection mode [16].

\subsubsection{Standby mode}

There is no voltage disturbance in standby mode, therefore the DVR does not need to inject any power into the grid, i.e $V_{D V R}=0$. Individual converter legs are triggered in this mode of operation to create a short circuit [17], [18], as shown in Figure 3.



Figure 2. Equivalent circuit of a DVR

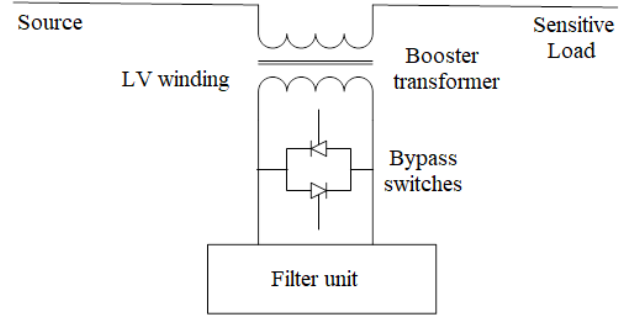

Figure 3. Standby mode of the DVR

\subsubsection{Injection mode}

As soon as a voltage sag is detected, the DVR operates in the injection mode and injects the appropriate compensation voltage into the grid through the booster transformer [17], [19].

\subsubsection{Protection mode}

The DVR will be disconnected from the system by bypass switches if the current on the load side exceeds a legal limit, such as during a load short circuit or excessive inrush current. To offer an alternative path for the load current, switches S2 and S3 will open and S1 will be closed, as shown in Figure 4 [19], [20].

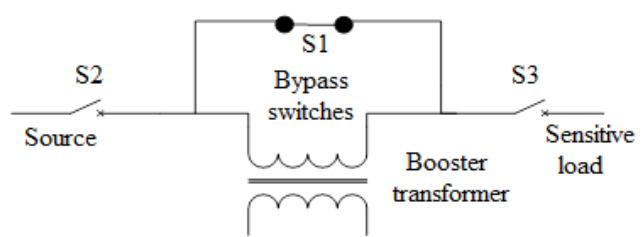

Figure 4. Protection mode 


\section{PROPOSED CONTROL SCHEME OF THE DVR} in Figure 5.

A detailed model of DVR and its control scheme is carried out under MATLAB/Simulink as shown

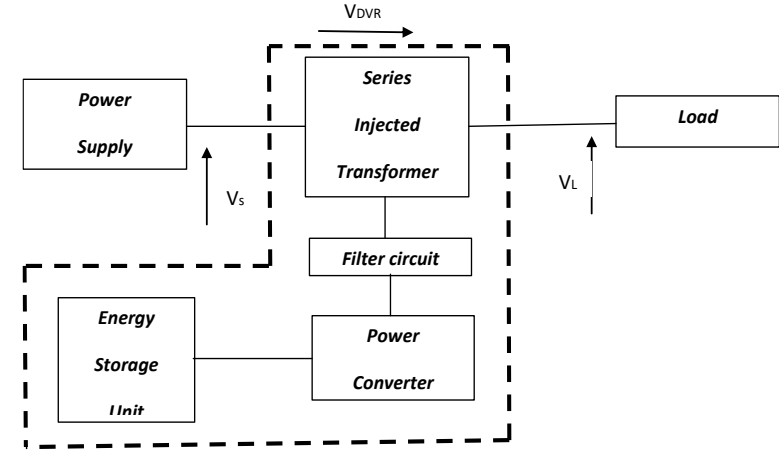

(a)

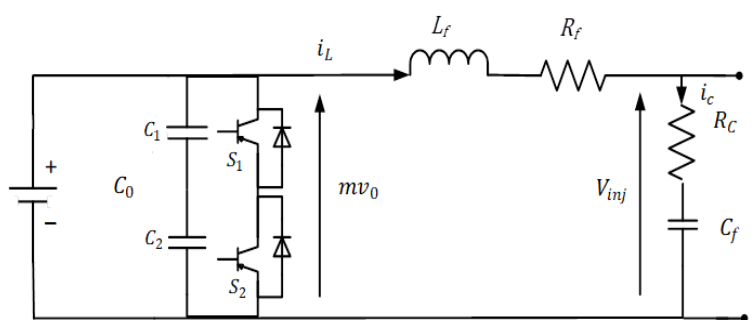

(b)

Figure 5. Diagram of single-ended electrical representation for DVR: (a) Typical DVR structure, (b) Series converter single-phase representation

In this way, the equivalent circuit of the DVR is illustrated in Figure 5(b). The use of Kirchhoff's law of tension with the closed-circuit AC obtains a mathematical formulation (3) and (4) [21].

$$
\begin{aligned}
& m v_{0}=i_{L} R_{f}+L_{f} \frac{d i_{L}}{d t}+v_{i n j} \\
& v_{i n j}=i_{c} R_{c}+\frac{1}{c_{f}} \int\left(i_{c} d t\right)
\end{aligned}
$$

with:

$m$ : Control input

$i_{L}:$ Inductor current of the series converter

$v_{i n j}:$ Output voltage

$v_{0}:$ dc link voltage

$L_{f}:$ Filtre inductance

$C_{f}:$ Filtre capacitance

$R_{f}$ : ESR of inductor

$R_{c}:$ ESR of capacitor.

\subsection{Sliding mode controller}

\subsubsection{Theory of SMC}

The sliding mode is a specific operation mode for systems with changeable structure. Variable structure control is a non-linear control by definition. The essential feature of systems with changeable structure is that their control laws evolve in a non-linear fashion. The design of regulators by sliding modes takes care of stability and desired performance problems in a systematic way. This control mechanism is primarily implemented in three parts: selection of the surface; the establishment of the conditions and the control law.

The SMC is used in the control of the DVR to improve its dynamic performance while attenuating voltage disturbances that penetrate the system connected to the DVR's network voltage. The following statespace model of the DVR was created by applying the concept of variable structure control to the basic structure of the connected DVR system, as shown in Figure 2.

$$
\left\{\begin{array}{l}
\frac{d V_{i n j}}{d t}=\frac{1}{C_{f}} i_{f}-\frac{1}{C_{f}} i_{S} \\
\frac{d i_{f}}{d t}=-\frac{1}{L_{f}} V_{i n j}-\frac{R_{f}}{C_{f}} i_{f}+\frac{1}{L_{f}} V_{d c} u
\end{array}\right.
$$


Where $i_{f}$ and $i_{s}$ represent the filter inductor current and source current respectively.

Taking the injected voltage $x_{1}=V_{i n j}$ and by derivate $x_{1}, \dot{x}_{1}=x_{2}$. Then, the model becomes (6).

$$
\left\{\begin{array}{l}
\dot{x}_{1}=x_{2} \\
\dot{x}_{2}=-\frac{1}{L_{f} C_{f}} x_{1}-\frac{R_{f}}{L_{f} C_{f}} x_{2}-\frac{R_{f}}{L_{f} C_{f}} i_{s}-\frac{1}{C_{f}} \frac{d i_{s}}{d t}+\frac{V_{d c}}{L_{f} C_{f}} u
\end{array}\right.
$$

First, consider the following general second order dynamic system as (7).

$$
\left\{\begin{array}{l}
\dot{x}_{1}=x_{2}+\theta_{1} \varphi_{1}\left(x_{1}\right) \\
\dot{x}_{2}=\theta_{2} \varphi_{2}\left(x_{1}, x_{2}\right)+b\left(x_{1}+x_{2}\right) u
\end{array}\right.
$$

Where, $\varphi_{i}(),. i=1,2$ are smoothing functions with continuous finite time derivatives and $b\left(x_{i}\right)$ is invertible. To simplify the equations, the arguments of $\varphi_{\mathrm{i}}($.$) and \mathrm{b}($.$) will be dropped in what follows. The parameters$ $\theta_{1}$ and $\theta_{2}$ are known. Let the output of the system be $V_{i n j}=x_{i}$ for $i=1,2$.The error is defined as (8) and (9) [22]:

$$
\begin{aligned}
& z_{1}=V_{i n j, r e f}-V_{i n j,}=V_{i n j, r e f}-x_{1} \\
& \left\{\begin{array}{l}
\dot{z}_{1}=\dot{V}_{\text {inj,ref }}-x_{2}-\theta_{1} \varphi_{1}=z_{2} \\
\dot{z}_{2}=\ddot{V}_{\text {inj,ref }}-\theta_{2} \varphi_{2}-b u-\theta_{1} \frac{\partial \varphi_{1}}{\partial x_{1}}+\left(x_{2}+\theta_{1} \varphi_{1}\right)
\end{array}\right.
\end{aligned}
$$

\subsubsection{Sliding surface selection} (11) [22].

Figure 6 shows the sliding surface. The sliding surface with its derivation can be defined as (10) and

$$
\begin{aligned}
& s=\lambda z_{1}+z_{2} \\
& \dot{s}=\lambda z_{2}+\dot{z_{2}}
\end{aligned}
$$

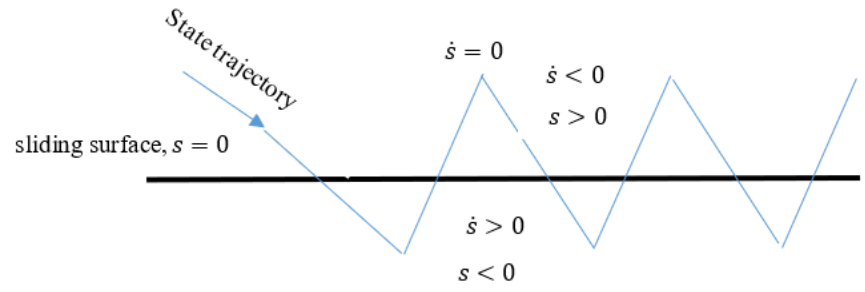

Figure 6. Sliding surface

After, using the following Lyapunov function: $V(s)=1 / 2 s^{2}$, then its time derivative is (12).

$$
\dot{V}(s)=s * \dot{s}
$$

For stability, $\dot{V}<0$, which results in $\dot{s}<0$ for $s>0$ and $\dot{s}>0$ for $s<0$. Then, using (11) and (9), the control law can be derived as (13).

$$
\mathrm{u}=\frac{1}{\mathrm{~b}}\left[\lambda \mathrm{z}_{2}+\ddot{\mathrm{V}}_{\mathrm{inj}, \mathrm{ref}}-\Theta_{2} \varphi_{2}-\theta_{1} \frac{\partial \varphi_{1}}{\partial \mathrm{x}_{1}}+\left(\mathrm{x}_{2}+\Theta_{1} \varphi_{1}\right)-\dot{\mathrm{s}}\right]
$$

The error can be defined as (14).

$$
V_{\text {inj ref }}(\mathrm{t})=V_{\text {load,ref }}-V_{s}(t)
$$


Where $V_{\text {load,ref }}$ is the desired reference load voltage at the point of common coupling (PCC). The error between $V_{\text {load,ref }}$ and $V_{\text {load }}$ gives the reference of the injected voltage signal provided by the injection transformer [23].

The instantaneous error signal $z_{1}$ is obtained by comparing the output of the low-pass filter with the injected reference voltage. The sliding mode controller then uses the error and its derivative $(e, \Delta e)$ to form the control law $\mathrm{u}$, which is converted to a PWM signal for switching the inverter IGBT devices [24], [25]. The error $z_{1}$ is derived using (15), (16) and (17). The Control block diagram of DVR as shown in Figure 7.

$$
\begin{aligned}
& z_{1}=V_{i n j, r e f}-V_{i n j}=V_{i n j, r e f}-x_{1} \\
& \dot{z}_{1}=\dot{V}_{i n j, r e f}-\dot{x}_{1}=\dot{V}_{i n j, r e f}-\dot{x}_{2}=\dot{z}_{2} \\
& \dot{z}_{2}=\dot{V}_{i n j, r e f}=\ddot{V}_{i n j, r e f}+\frac{R_{f}}{L_{f}} \dot{V}_{i n j, r e f}+\frac{1}{L_{f} C_{f}} \dot{V}_{i n j, r e f}-\frac{1}{L_{f} C_{f}} z_{1}-\frac{R_{f}}{L_{f}} Z_{2}+\frac{R_{f}}{L_{f} C_{f}} i_{s}+\frac{1}{C_{f}} \frac{d i_{s}}{d t}-\frac{V_{d c}}{L_{f} C_{f}} u
\end{aligned}
$$



Figure 7. Control block diagram of DVR

The selected sliding surface was $s=K_{1} z_{1}+K_{2} z_{2}$ along with the control law as (18).

$$
\dot{s}=f(s) * K \operatorname{sgn}(s)
$$

Where (19)

$$
f(s)=-[1 / \mathrm{q}(\mathrm{s})]
$$

And $q(s)$ is given by (20)

$$
q(s)=\left[\gamma+(1-\gamma) e^{-\alpha|s|} \cos (\beta|s|)\right]
$$

After, using (12) to obtain the SM control law.

\subsubsection{Determination of control law}

Finally, the control law can be derived using (12), (17) and (18) as (21).

$$
u=\frac{L_{f} C_{f}}{V_{d c}}\left[\frac{k_{1}}{k_{2}} z_{2}+\ddot{V}_{\text {inj,ref }}+\frac{1}{L_{f} C_{f}} x_{1}+\frac{R_{f}}{L_{f}} x_{1}+\frac{R_{f}}{L_{f} C_{f}} i_{s}+\frac{1}{C_{f}} \frac{d i_{s}}{d t}\right]+\frac{1}{k_{2}}\left[\frac{k \cdot s g n(s)}{q(s)}\right]
$$

\section{EXPERIMENTAL STUDY OF THE DVR}

This section discusses the hardware used to design the experimental set-up of the DVR and its auxiliary circuits. 


\subsection{Experimental setup of the DVR}

Figure 8 shows the experimental set-up of the DVR and overall system block diagram designed in this work for mitigation of voltage sags/swells and harmonics. Parameters of the DVR hardware setup as shwon in Table 1. The single-phase DVR consists of the following components [26]:
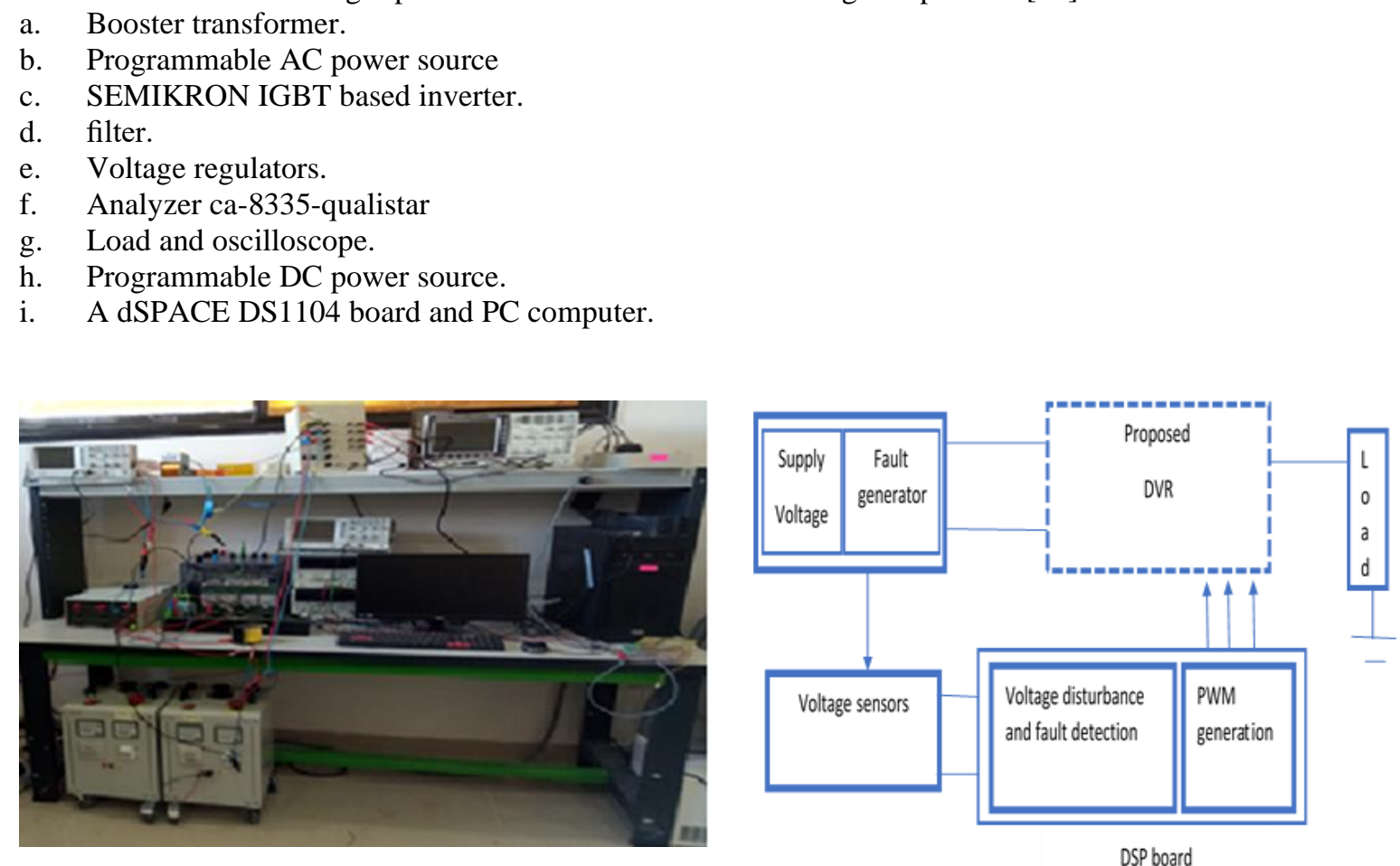

Figure 8. Experimental set-up of the single-phase DVR and overall system block diagram

Table 1. Parameters of the DVR hardware setup

\begin{tabular}{ll}
\hline \multicolumn{1}{c}{ Parameters } & \multicolumn{1}{c}{ Values } \\
\hline Supply voltage, $\boldsymbol{V}_{\boldsymbol{s}}$ & $8.5 \mathrm{Vrms}$ \\
Load resistance, $\boldsymbol{R}_{\boldsymbol{L}}$ & $20 \Omega$ \\
LC filter capacitance, $\boldsymbol{C}_{\boldsymbol{f}}$ & $1 \mathrm{nF}$ \\
LC filter inductance, $\boldsymbol{L}_{\boldsymbol{f}}$ & $24.6 \mathrm{mH}$ \\
Transformer & $12 \mathrm{~V} / 230 \mathrm{~V} / 1 \mathrm{kVA}$ \\
DC-bus capacitor & $2200 \mu \mathrm{F}$ \\
Reference voltage, $\boldsymbol{V}_{\boldsymbol{d} \boldsymbol{c}}^{*}$ & \multicolumn{1}{c}{$37 \mathrm{~V}$} \\
\hline
\end{tabular}

\subsection{Experiment results}

To validate the simulation results of the proposed DVR control method, an experimental test designed under a Texas Instruments dSPACE card 1104 platform, inserted into a Pentium PC allowing for automatic implementation of the algorithms of the control. Design of prototypeof DVR and its performance during voltage sag and swell condition is elaborated both for load.

The experimental results of a single-phase DVR are described in this part to demonstrate the capabilities of the proposed DVR for load-side voltage regulation. The switching frequency of the converter is set at $20 \mathrm{kHz}$. Only the faults generated by the source have been considered. The load-generated faults are not explored in this work.

Two experimental tests are presented. The first test aims to demonstrate the ability of proposed DVR in compensating voltage sags for a period of a few cycles. In this test, it is assumed that the system can experience a voltage sag of up to $38 \%$ of the nominal voltage, the injected voltage is in phase. The results are shown in Figure 9. On the left panel, are shown snapshots of the voltages and the right panel shows the zoomed waveforms. 


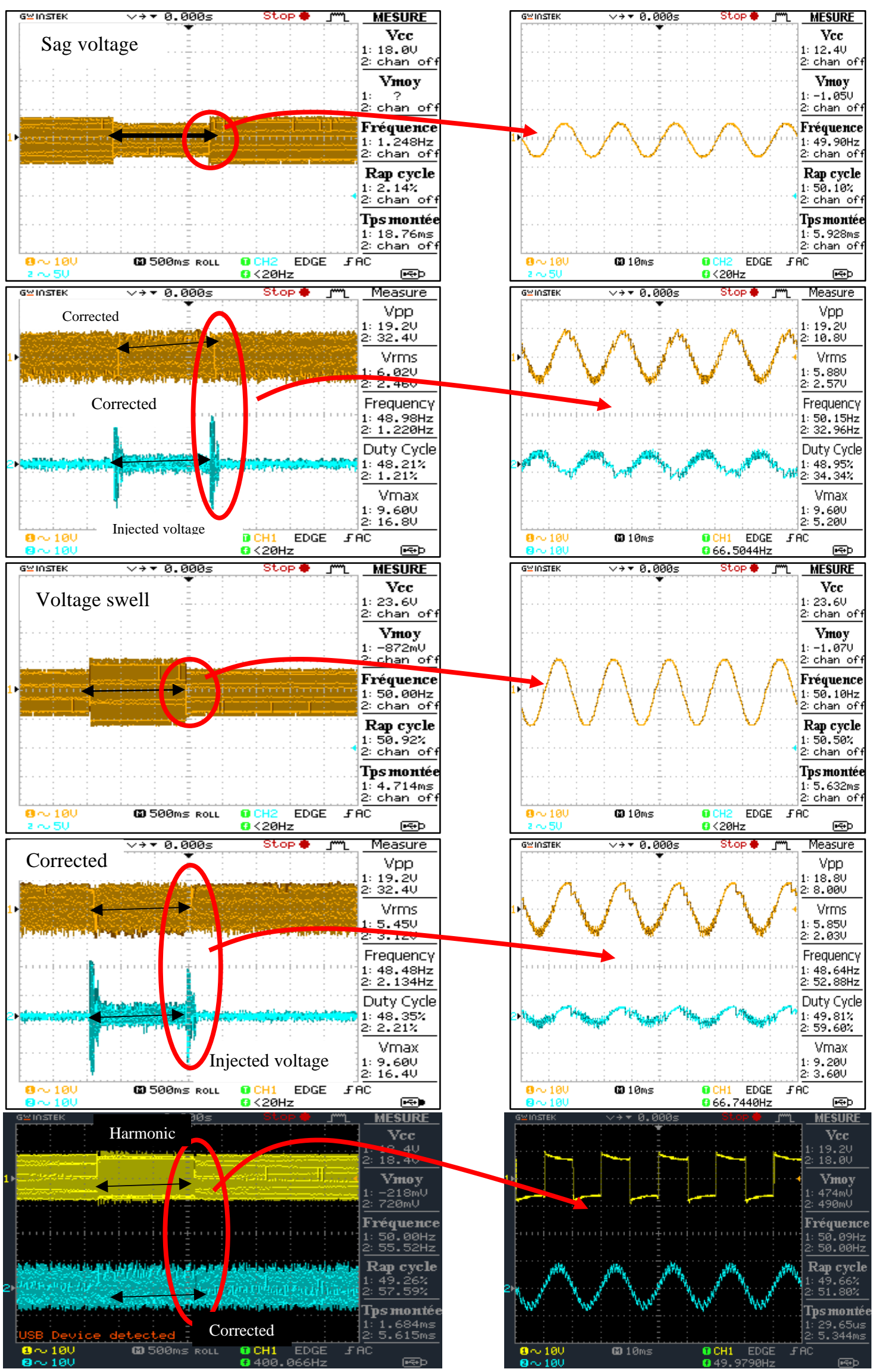

Figure 9. Experimental results: Voltage sag/swell and harmonics 
The second experiment is aimed to test the ability of the proposed DVR control scheme to compensate voltage swells; injected voltage is out of phase. To simulate this fault scenario, the source voltage is increased by $20 \%$ for a period of a few cycles as shown in Figure 9 . Once the fault is cleared, the source voltage is restored to its initial value. Both voltage sag and swell are initiated at $\mathrm{t}=12.8 \mathrm{~s}$ and cleared at $\mathrm{t}=15.8 \mathrm{~s}$, i.e., they last for $3 \mathrm{~s}$. An injection transformer connected between the supply and the load compensates the load voltage by injecting a voltage in series with the supply voltage.

Harmonics can be eliminated using the proposed DVR. To demonstrate the suggested DVR's capabilities, it is assumed that the source voltage is significantly distorted due to harmonics. Figure 10 depicts the results.

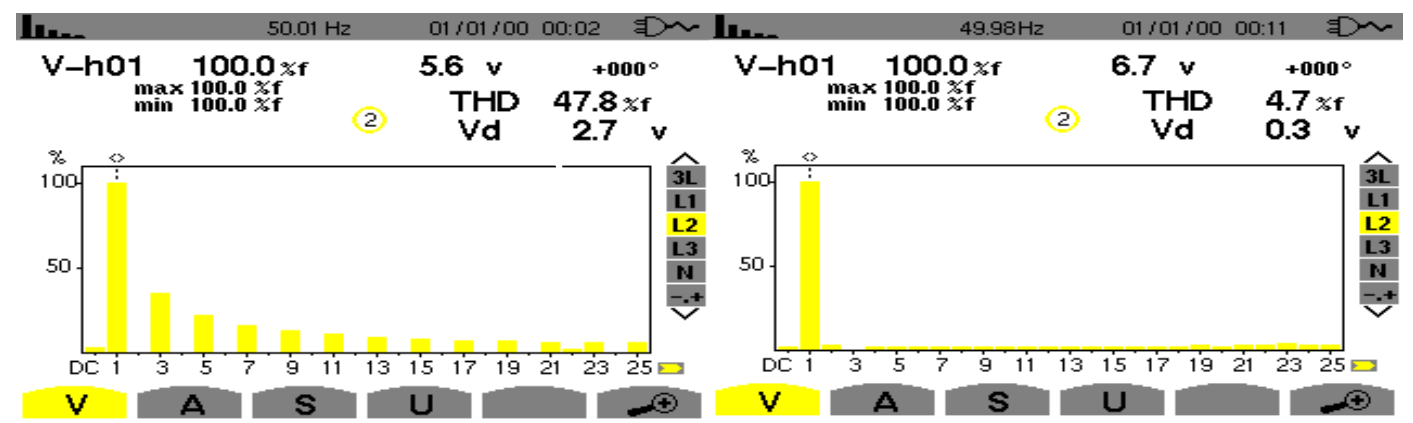

Figure 10. Total harmonic distortion. Electrical grid and Protected load

\section{CONCLUSION}

A dynamic voltage restorer is employed in this study to mitigate voltage sags in the distribution system, there by improving the performance of the system. As a result, the quality of the output voltage waveform is significantly improved. In a MATLAB environment, the DVR was modeled and simulated, and its performance was evaluated under fault situations with a linear load. The results show that the DVR is able of improving power quality in distribution systems. In the present paper a fuzzy logic-based controller was proposed the DVR. This topology can be easily extended to n-phase systems such as three-phase based on the same principle of the operation, it's not needing high voltage switches when it operates.

The ability of SMC-based DVR to compensate for disturbance of voltage on the distribution side has been validated experimentally ad a good dynamic response has been achieved for the fault conditions considered. The compensated voltage in harmonics case was within the IEEE standards IEEE 519-1992 and IEEE 1159-1995.

\section{ACKNOWLEDGEMENTS}

The authors are grateful for a research grant from DGRSDT (General Direction of Scientific Research and Technological Development.

\section{REFERENCES}

[1] M. H. J. Bollen, "Understanding power quality problems" voltage sags and interruptions, New York: IEEE press, 2000.

[2] C. Jayashankar, R. Ilango, V. Prabaharan "Single phase dynamic voltage restorer for abnormal conditions," International Journal of Engineering and Applied Sciences, vol. 2, no. 4, 2015

[3] H. Abdollahzadeh, M. Jazaeri, A. Tavighi "A new fast-converged estimation approach for Dynamic Voltage Restorer (DVR) to compensate voltage sags in waveform distortion conditions," International Journal of Electrical Power \& Energy Systems, vol. 54, pp. 598-609, 2016, doi: 10.1016/j.ijepes.2013.08.012.

[4] N. M. Salgado-Herrera, A. Medina-Rios, R. Tapia-Sánchez, O. Anaya-Lara and J. R. Rodríguez-Rodríguez, "Sags and swells compensation and power factor correction using a dynamic voltage restorer in distribution systems," 2017 IEEE International Autumn Meeting on Power, Electronics and Computing (ROPEC), 2017, pp. 1-6, doi: 10.1109/ROPEC.2017.8261633.

[5] S. A. Taher, H. T. Fard and E. B. Kashani, "New switching approach for DVR using one cycle control method," Ain Shams Engineering Journal, vol. 9, no. 4, pp. 2227-2254, 2018, doi: 10.1016/j.asej.2017.03.003.

[6] M. Tumay, A. Teke, K. Cagatay, M. Bayindir and U. Cuma, "Simulation and modeling of a dynamic voltage restorer," In: Proc ELECO, Turkey, 2006, pp. 1-5. 
[7] D. N. Kalote, M. B. Daigavane, S. P. Gawade and P. M. Daigavane, "Analysis, design and implementation of single phase SRF controller for dynamic voltage restorer under distorted supply," Energy Procedia, vol. 117, pp: 716-723, 2017, doi: 10.1016/j.egypro.2017.05.186.

[8] E. Babaei, M. F. Kangarlu and M. Sabahi, "Mitigation of voltage disturbances using dynamic voltage restorer based on direct converters," in IEEE Transactions on Power Delivery, vol. 25, no. 4, pp. 2676-2683, Oct. 2010, doi: 10.1109/TPWRD.2010.2054116.

[9] E. Babaei and M. F. Kangarlu, "Operation and control of dynamic voltage restorer using single-phase direct converter," Energy Conversion and Management, vol. 52, no. 8-9, pp. 2965-2972, 2011, doi: 10.1016/j.enconman.2011.04.014.

[10] H. Ezoji, A. Sheikholeslami, M. Rezanezhad and H. Livani, "A new control method for dynamic voltage restorer with asymmetrical inverter legs based on fuzzy logic controller," Simulation Modelling Practice and Theory, vol. 18, no. 6, pp. 806-819, 2010, doi: 10.1016/j.simpat.2010.01.017.

[11] A. Meena, S. Islam, S. Anand, Y. Sonawane and S. Tungare, "Design and control of single-phase dynamic voltage restorer," Sadhana, vol. 42, no. 8, pp. 1363-1375, 2017, doi: 10.1007/s12046-017-0653-5.

[12] J. G. Nielsen, M. Newman, H. Nielsen and F. Blaabjerg, "Control and testing of a dynamic voltage restorer (DVR) at medium voltage level," in IEEE Transactions on Power Electronics, vol. 19, no. 3, pp. 806-813, May 2004, doi: 10.1109/TPEL.2004.826504.

[13] A. Ghosh and G. Ledwich, "Power quality enhancement using custom power devices," Kluwer Academic Publishers, 2002.

[14] M. Nabipour, M. Razaz, S. GH. Seifossadat and S. S. Mortazavi, "A novel adaptive fuzzy membership function tuning algorithm for robust control of a PV-based Dynamic Voltage Restorer (DVR)," Engineering Applications of Artificial Intelligence, vol. 53, pp. 155-175, 2016, doi: 10.1016/j.engappai.2016.04.007.

[15] T. Toumi, A. Allali, O. Abdelkhalek, A. BenAbdelkader, A. Meftouhi, and M. A. Soumeur, "PV Integrated singlephase dynamic voltage restorer for sag voltage, voltage fluctuations and harmonics compensation," International Journal of Power Electronics and Drive Systems (IJPEDS), vol. 11, no. 1, pp. 547-554, 2020, doi: 10.11591/ijpeds.v11.i1.pp547-554.

[16] S. Ezhilarasan, G. Balasubramanian, "DVR for voltage sag mitigation using PI with fuzzy logic controller," International Journal of Engineering Research and Applications, vol. 3, no. 1, pp. 1090-1095, 2013

[17] R. Omar and N. A. Rahim, "Modeling and simulation for voltage sags/swells mitigation using dynamic voltage restorer (DVR)," 2008 Australasian Universities Power Engineering Conference, 2008, pp. 1-5.

[18] M. Khodja, D. Rahiel, M.B. Benabdallah, H. Merabet Boulouiha, A. Allali, A. Chaker and M. Denai, "Highperformance multicell series inverter-fed induction motor Drive", Electrical Engineering, vol. 99, pp. 1121-1137 2017, doi: 10.1007/s00202-016-0472-4

[19] N. Hamzah, M. R. Muhamad and P. M. Arsad, "investigation on the effectiveness of dynamic voltage restorer for voltage sag mitigation," 2007 5th Student Conference on Research and Development, 2007, pp. 1-6, doi: 10.1109/SCORED.2007.4451447.

[20] A. K. Jena, B. Mohapatra and K. Pradhan, "Modeling and simulation of a dynamic voltage restorer (DVR)", Project Report, Bachelor of Technology in Electrical Engineering, Department of Electrical Engineering, National Institute of Technology, Rourkela, Odisha-769008.

[21] A. B. Abdelkader, O. Abdelkhalek, M. A. Soumeur, O. Hafsi, A. Chakar, "Simulation and experimental validation of single-phase series active power filter using PI and backstepping nonlinear controllers," International Journal of Applied Power Engineering (IJAPE), vol. 9, no. 1, pp. 78-88, April 2020, doi: 10.11591/ijape.v9.i1.pp78-88.

[22] A. Pandey, R. Agrawal, R. S. Mandloi and B. Sarkar. "sliding mode control of dynamic voltage restorer by using a new adaptive reaching law," Journal of The Institution of Engineers (India), vol. 98, no. 6, pp. 579-589, 2017, doi: 10.1007/s40031-017-0289-1.

[23] R. R. Errabelli, Y. Y. Kolhatkar and S. P. Das, "Experimental investigation of DVR with sliding mode control," 2006 IEEE Power India Conference, 2006, pp. 5, doi: 10.1109/POWERI.2006.1632533.

[24] T. Toumi, A. Allali, A. Meftouhi, O. Abdelkhalek, A. Benabdelkader, and M. Denai, "Robust control of series active power filters for power quality enhancement in distribution grids: Simulation and experimental validation," ISA transactions, vol. 107, pp. 350-359, 2020, doi: 10.1016/j.isatra.2020.07.024.

[25] T. Toufik, A. Ahmed, A. Othmane, and S. M. Amine, "Control DC link of single-phase dynamic voltage restorer," International Journal of Applied Power Engineering (IJAPE), vol. 9, no. 3, pp. 297-304, 2020, doi: 10.11591/ijape.v9.i3.pp297-304.

[26] T. Toumi, A. Allali, O. Abdelkhalek, J. M. Guerrero, Y. Terriche, M. A. Soumeur, "Voltage quality improvement in electrical distribution networks using dynamic voltage restorers: Design, simulation and experimental tests of a robust controller," Electrical Engineering, vol. 103, no. 3, pp. 1661-1678, 2021, doi: 10.1007/s00202-020-01158-5. 